\title{
EFFECT OF CURRENT MODE ON THE PLASMA DISCHARGE, MICROSTRUCTURE AND CORROSION RESISTANCE OF OXIDE COATINGS PRODUCED ON 1100 ALUMINUM ALLOY BY PLASMA ELECTROLYTIC OXIDATION
}

\author{
RIYAD O. HUSSEIN ${ }^{1}$, XUEYUAN NIE ${ }^{2} \&$ DEREK O. NORTHWOOD ${ }^{2}$ \\ ${ }^{1}$ Natural Sciences Division, Higher Colleges of Technology, United Arab Emirates \\ ${ }^{2}$ Department of Mechanical, Automotive and Materials Engineering, University of Windsor, Canada
}

\begin{abstract}
Oxide coatings were produced on an 1100 aluminum alloy using a plasma electrolytic oxidation (PEO) process in an alkali-silicate electrolyte. Three different current modes were investigated, namely DC, unipolar and bipolar. Optical emission spectroscopy (OES) was used to characterize the plasma in terms of the plasma electron concentration and temperature. SEM and EDS were used to characterize the surface morphology and the cross-sectional structure of the coatings. Potentiodynamic polarization corrosion testing was performed in $3.5 \mathrm{wt} \% \mathrm{NaCl}$ solution for both uncoated and coated samples. Plasma electron temperatures were in the range of $4,500 \mathrm{~K}$ to $10,000 \mathrm{~K}$. The plasma characteristics, including sparking, have been related to the surface morphology of the coating. The coating morphology, microstructure and corrosion resistance varied with current mode. A bipolar current mode produced a higher quality (surface morphology, compactness and corrosion resistance) coating than either a DC or unipolar mode.
\end{abstract}

Keywords: PEO coatings, process parameters, plasma characteristics, soft sparking, coating quality, corrosion.

\section{INTRODUCTION}

Aluminum and its alloys are important structural materials in the automotive, aerospace and transportation industries [1], [2]. In order to improve surface properties, such as wear and corrosion resistance, various surface treatments have been employed including electrochemical treatments, chemical treatments and coatings [3], [4]. Of the electrochemical treatments, anodizing, where the metal in converted to an oxide coating, has found widespread usage [5]. However, conventional anodized coatings do not provide sufficient wear and corrosion resistance for specific applications [6].

Plasma electrolytic oxidation (PEO), also known as micro-arc oxidation (MAO), is a surface coating technology that is related to anodizing, but produces coatings that are superior in metal protection to those formed by anodizing or chemical treatment [7], [8]. PEO is operated at a voltage (400-600 V) exceeding the dielectric breakdown of the anodic oxide first formed at the surface. Sparks move across the surface, form a plasma envelope, and oxidize the surface As sparking proceeds the oxide grows and consolidates, and its adhesion to the surface is improved [7]. The mechanisms of coating growth are complex but essentially involve electrochemical reactions, plasma-chemical reactions and thermal (oxygen) diffusion [9]-[13].

The formation and structure (microstructure; phases; porosity; stress state) of the coatings depend on the PEO processing parameters, including electrical parameters (current density, frequency, duty cycle; type of current (DC, AC, pulsed-unipolar and bi-polar), electrolyte composition, deposition time and substrate composition [6], [10], [11], [14], [15]. Changes in the PEO processing parameters give rise to changes in the microdischarge characteristics, 
which determine the thermal and chemical conditions on the oxidizing surface [16], and thus the structure of the resultant oxide coating. To produce the desired structure, it is now recognized that it is necessary to prompt a soft sparking transition where there is a sudden decrease in light and acoustic emissions, and drop in the anodic voltage when operating under a controlled current mode [7].

Several approaches have been employed for PEO process diagnostics including optical, spectral, electrical, acoustic, frequency response and electrochemical impedance spectroscopy [17]. Optical emission spectroscopy (OES) can provide valuable information on the plasma characteristics including electron number density, ionization temperature and elemental composition. This information is useful in understanding the coating formation process, and in the development of PEO and associated processes [18].

In the present study, the effect of current mode (DC, unipolar or bipolar) was investigated for the PEO processing of 1100 aluminum alloy in an alkali-silicate electrolyte. OES was used to characterize the plasma (electron concentration and temperature). The plasma characteristics, including sparking, are correlated both to the coating surface morphology, microstructure and composition, and to the corrosion resistance of the coated and uncoated alloy.

\section{EXPERIMENTAL PROCEDURES}

\subsection{Material}

A 1100 aluminium alloy was used for the study. The composition was Al- $0.10 \% \mathrm{Cu}-0.15 \%$ Fe- $0.05 \%$ Si- $0.05 \% \mathrm{Zn}$. Specimens with dimensions $25 \mathrm{~mm}$ x $25 \mathrm{~mm}$ x $5 \mathrm{~mm}$ were cut from the sheet. They were manually ground and polished with 240, 400, 600 and 1200 grid $\mathrm{SiC}$ papers to a surface finish of $0.1 \pm 0.02 \mu \mathrm{m}$. After cleaning with water, they were degreased with acetone prior to $\mathrm{PEO}$ processing.

\subsection{PEO processing}

A schematic of the PEO system is given in Fig. 1. The electrolyte used was an alkaline solution containing sodium silicate $\left(\mathrm{Na}_{2} \mathrm{SiO}_{3}\right)$ at two levels of concentration $(4$ and $8 \mathrm{~g} / \mathrm{l})$ and potassium hydroxide $(1 \mathrm{~g} / \mathrm{l} \mathrm{KOH})$. The electrolyte was kept below $25^{\circ} \mathrm{C}$ by a water cooling system. The system was operated under a constant current control function in three different current modes (DC, unipolar, bipolar). Since the conductance of the oxide film decreases with coating thickness, the input voltage between anode and cathode must be increased to maintain the current density. Voltage versus PEO treatment time was recorded for each sample. Further details of the PEO system can be found in [19], [20].

\subsection{OES and diagnostics}

Since the discharges occur randomly, the OES measurements were made using an integrated signal over the whole sample surface. An Ocean Optics PC2000-UV-VIS fiber optic spectrometer, with a 200-1100 nm range was used. Six different spectral lines were recorded. Prior to the experimentation, the spectrometer was calibrated using two different laser beams: $\mathrm{He}-\mathrm{Cd}(441.6 \mathrm{~nm})$ and $\mathrm{He}-\mathrm{Ne}(632.8 \mathrm{~nm})$. Further details of the instrumentation can be found in [19].

The electron density can be determined through the Stark broadening of the H $\beta$ line. Stark broadening is the broadening due to interaction with charged particles. The hydrogen lines 


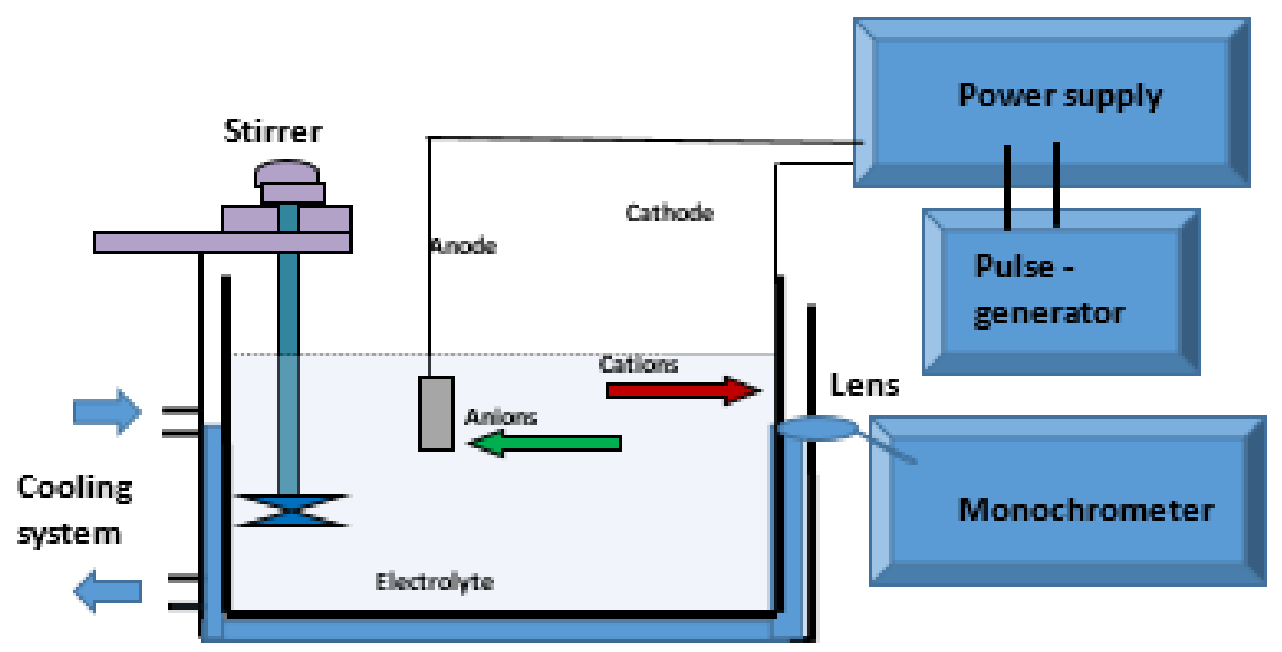

Figure 1: Schematic diagram of the PEO coating system.

$\mathrm{H} \beta$ are wide so that they are easy to record and process without perturbing the plasma. The PEO plasma falls into the category of an optically thin plasma, i.e. none of the observed lines emitted from the plasma were affected by self-absorption [21], [22]. For a hydrogen line profile, the relationship between full half-widths FWHM (full width at half maximum intensity) $\Delta \lambda_{1 / 2}$ in $\mathrm{nm}$ and electron concentration $\mathrm{Ne}$ in $\mathrm{m}^{-3}$ is given by [23]:

$$
\Delta \lambda_{1 / 2}=4.80\left(\frac{N_{e}}{10^{23}}\right)^{0.68116} .
$$

As a cross check, and to include the effect of electron temperature on the electron density calculation, the formula by Czernikowski and Chapelle [24], using the Stark broadening in the line at half-width $\left(\Delta \lambda_{1 / 2}\right)$ was used where [25]:

$$
\log \mathrm{Ne}=\mathrm{c}_{0}+\mathrm{c}_{1} \log \Delta \lambda_{1 / 2}+\mathrm{c}_{2}\left(\log \Delta \lambda_{1 / 2}\right)^{2}+\mathrm{c}_{3} \log \mathrm{Te},
$$

with $\mathrm{c}_{0}=22.758 ; \mathrm{c}_{1}=1.478 ; \mathrm{c}_{2}=-0.144 ;$ and $\mathrm{c}_{3}=-0.1265, \Delta \lambda_{1 / 2}$ being given in $\mathrm{nm}$, Te in $\mathrm{K}$ and electron density in $\mathrm{cm}^{-3}$.

The plasma electron temperature Te, was determined from the relative intensities of spectral lines of the same atomic species from the same ionization stage as detailed in [19], [26].

\subsection{Materials characterization}

A FEI Quanta 200 FEG SEM equipped with a Kevex 5100c energy dispersive x-ray analysis detector (EDS) was used to characterize the coated specimens for surface morphology, coating thickness, integrity (cross-sectional samples) and chemical composition.

A Solartron 1285 Potentiostat with a Corrware Software was used for the potentiodynamic polarization corrosion testing. Corrosion testing was conducted in a $3.5 \% \mathrm{NaCl}$ solution. 


\section{RESULTS AND DISCUSSION}

\subsection{Voltage variation during PEO processing}

Fig. 2 presents plots of the anodic voltage vs treatment time for the three current modes with a $4 \mathrm{~g} / 1 \mathrm{Na}_{2} \mathrm{SiO}_{3}$ electrolyte. Four stages can be seen in the PEO process [19]. In Stage I, the rapid rise in the voltage corresponds to a conventional aluminium anodizing process. Above a critical voltage, the anodic film undergoes dielectric breakdown [27] small sparks are generated which facilitates continued growth of the oxide film. This is Stage II, and the rate of voltage change with time decreases. The rate of voltage change slows down further in Stage III. In Stage IV, the rate of voltage change is even slower than in Stage III, and remained almost constant at $1 \mathrm{volt} / \mathrm{min}$ for all three current modes.

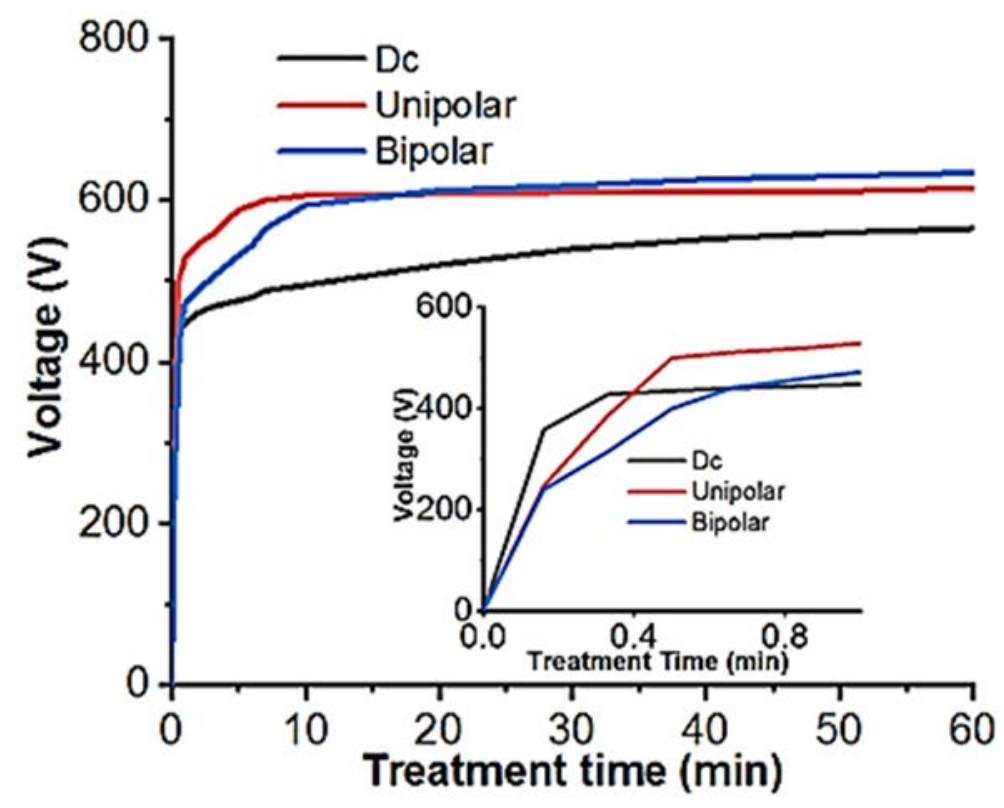

Figure 2: Plots of anodic voltage (V) vs. treatment time (t) for $4 \mathrm{~g} / 1 \mathrm{Na}_{2} \mathrm{SiO}_{3}$ electrolyte using three different current modes. (Insert is an enlargement for the first minute.)

Table 1 summarizes the breakdown voltages and the time periods for the four stages. Stage 1 , before breakdown, is very short $(<20$ seconds). Stage II, occurs for times up to 10 minutes. Stage III for times up to 40 minutes. Stage IV occurs for processing times up to 60 minutes, the maximum processing time investigated. The breakdown voltage was the highest (358 V) for the DC current mode: over $100 \mathrm{~V}$ higher than the unipolar or bipolar current. The magnitude of the breakdown voltage has conventionally been correlated to the conductivity of the electrolyte but recent work by Simchen et al. has shown that it depends on the physicochemical properties of the anodic film, which is defined by the substrate material [28]. In the present tests, the substrate material was always 1100 aluminium alloy. If Simchen et al. [28] are correct, then it is suggested that the change in current mode changes "the physicochemical properties of the anodic film". 
Table 1: Breakdown voltages and durations of the four PEO stages for different current modes and a $4 \mathrm{~g} / 1 \mathrm{Na}_{2} \mathrm{SiO}_{3}$ electrolyte.

\begin{tabular}{|c|c|c|c|c|c|}
\hline \multirow{2}{*}{$\begin{array}{c}\text { Current } \\
\text { mode }\end{array}$} & \multicolumn{2}{|c|}{ Stage I } & Stage II & $\begin{array}{c}\text { Stage } \\
\text { III }\end{array}$ & Stage IV \\
\cline { 2 - 6 } & $\begin{array}{c}\text { Breakdown } \\
\text { voltage }\end{array}$ & $\begin{array}{c}\text { Period } \\
\text { (min) }\end{array}$ & $\begin{array}{c}\text { Period } \\
\text { (min) }\end{array}$ & $\begin{array}{c}\text { Period } \\
\text { (min) }\end{array}$ & $\begin{array}{c}\text { Period } \\
\text { (min) }\end{array}$ \\
\hline DC & 358 & $0-0.3$ & $0.3-3.0$ & $3-40$ & $40-60$ \\
\hline Unipolar & 247 & $0-0.2$ & $0.2-5$ & $5-22$ & $22-60$ \\
\hline Bipolar & 240 & $0-0.2$ & $0.2-10$ & $10-28$ & $28-60$ \\
\hline
\end{tabular}

3.2 Plasma electron density and temperature

Fig. 3 presents a typical Lorentz profile of the experimental data of $\mathrm{H}_{B}$ for the unipolar current mode at a specific time (15 minutes from the start of the process), with a peak width (FWHM) of $1.45 \mathrm{~nm}$. In the current experiments, FWHM values between 1.3 and $1.8 \mathrm{~nm}$ were recorded. Using both eqns (1) and (2), these half-widths correspond to a plasma electron concentration in a range of approximately $1.5 \pm 0.23 \times 10^{22} \mathrm{~m}^{-3}$ to $2.4 \pm 0.36 \times 10^{22} \mathrm{~m}^{-3}$ which are in good agreement with the plasma electron concentration results of Klapkiv et al. [29]. The error in measuring the electron concentration $\left(\delta N_{e} / N_{e}\right.$ ) is determined to be $\approx 15 \%$ [26], which is a reasonable value in such experiments [26].

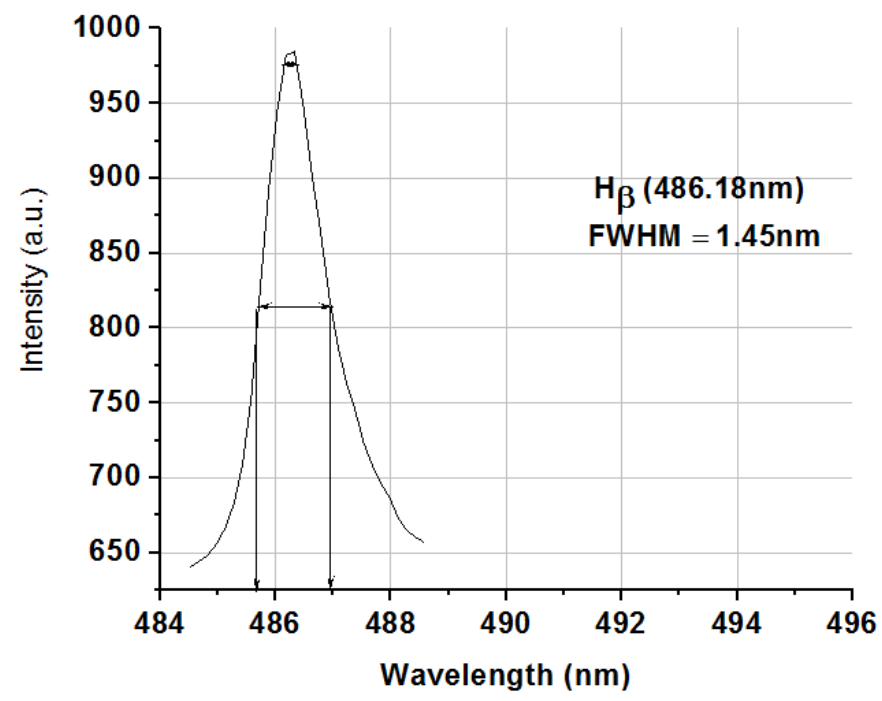

Figure 3: Typical results of a Lorentz profile of $\mathrm{H}_{\beta}$

When using spectral information to calculate parameters of the discharge, two assumptions are usually made: (1) The plasma is optically thin, which is the case for PEO [21], [22] and (2) There is local thermodynamic equilibrium (ETL). A partial LTE was expected where the electron density yield is given by [26]: 


$$
N_{e} \geq 7.0 \times 10^{24} \frac{Z^{7}}{n^{17 / 2}}\left(\frac{k T}{Z^{2} E_{H}}\right)^{1 / 2}\left(m^{-3}\right),
$$

where $\mathrm{kT}$ is the electron temperature in $(\mathrm{eV}), \mathrm{E}_{\mathrm{H}}(\mathrm{eV})$ is the ionization potential for the corresponding element, $\mathrm{z}$ is the ionization stage $(\mathrm{z}=1$ for $\mathrm{H})$ and $\mathrm{n}$ is the principle quantum number of the lowest quantum level included in the partial LTE $(n=2)$. The plasma electron concentration obtained in this work $\left(1.5-2.4 \times 10^{22} \mathrm{~m}^{-3}\right)$ is higher than the minimum plasma electron concentration for partial LTE, $\mathrm{Ne}>0.4 \times 10^{22} \mathrm{~m}^{-3}$, and therefore partial LTE exists, and the electron temperature estimated by Boltzmann assumption and Stark broadening effect is valid.

The intensity ratio of $396.2 \mathrm{~nm}(\mathrm{Al} \mathrm{I})$ to $309.1 \mathrm{~nm}$ (Al I) was used to measure the plasma temperature (Te). Fig. 4 is a plot of the plasma temperature vs PEO processing time for the three current modes with an electrolyte concentration of $4 \mathrm{~g} / 1 \mathrm{Na}_{2} \mathrm{SiO}_{3}$. Table 2 summarizes the baseline, minimum and maximum temperatures for the three current modes at the two electrolyte concentrations. Temperatures ranged from about $4,000 \mathrm{~K}$ to $10,000 \mathrm{~K}$. The low temperature represent the early stage discharges. The strong peaks $(6,000-10,000 \mathrm{~K})$ correspond to relatively strong discharges. Application of a bipolar current mode, virtually eliminates the very strong discharges and the electron temperature rarely exceeds $6,000 \mathrm{~K}$. Comparing that data in Table 2 for the two $\mathrm{Na}_{2} \mathrm{SiO}_{3}$ concentrations in the electrolyte $(4 \mathrm{~g} / \mathrm{l}$ and $8 \mathrm{~g} / \mathrm{l}$ ), it can be readily seen that the baseline temperatures are lower for $8 \mathrm{~g} / \mathrm{l}$ electrolyte. This is likely related to the higher electrical conductivity of the electrolyte.

Table 2: Electron temperatures for different electrolyte concentrations (4 and $8 \mathrm{~g} / \mathrm{l}$ $\mathrm{Na}_{2} \mathrm{SiO}_{3}$ ) and current modes.

\begin{tabular}{|c|c|c|c|c|c|c|}
\hline \multirow{2}{*}{$\begin{array}{c}\text { Current } \\
\text { mode }\end{array}$} & \multicolumn{3}{|c|}{ 4/l $\mathrm{Na}_{2} \mathrm{SiO}_{3}$} & \multicolumn{3}{c|}{ 8 g/l Na2SiO } \\
\cline { 2 - 7 } & $\begin{array}{c}\text { Base line } \\
\text { Temp(K) }\end{array}$ & $\begin{array}{c}\text { Minimum } \\
\text { Temp (K) }\end{array}$ & $\begin{array}{c}\text { Maximum } \\
\text { Temp(K) }\end{array}$ & $\begin{array}{c}\text { Base line } \\
\text { Temp(K) }\end{array}$ & $\begin{array}{c}\text { Minimum } \\
\text { Temp(K) }\end{array}$ & $\begin{array}{c}\text { Maximum } \\
\text { Temp(K) }\end{array}$ \\
\hline DC & 5,200 & 3,900 & 8,500 & 5,000 & 3,900 & 8,600 \\
\hline Unipolar & 5,600 & 3,900 & 10,000 & 5,100 & 3,950 & 8,300 \\
\hline Bipolar & 5,400 & 4,600 & 6,000 & 4,800 & 4,200 & 5,700 \\
\hline
\end{tabular}

It is interesting to compare the electron densities and temperatures for PEO to those in a lightning step leader, where the discharge channel is also optically thin and is in local thermodynamic equilibrium [30]. Electron densities of $10^{24} \mathrm{~m}^{-3}$ [30] and temperatures of $\sim 14,000 \mathrm{~K}[30]$, [31] have been reported for lightning. The electron densities and temperature decrease as the lightning stepped leader propagates towards the ground.

\subsection{Morphology, microstructure and chemistry of coatings}

Fig. 5 presents SEM micrographs of the surface morphology of the coatings produced after 60 minutes treatment time. All samples showed a distinct "pancake" structure in which the hole at the center of the "pancake" is the discharge channel through which molten aluminium was ejected, sintered, and rapidly solidified by electrolyte. Fig. 5 are also shows micropores and cracks of different size, which helps to release residual stress in the coating. The size and density of the pores reflecting the strength of the discharges that produced the pores. 


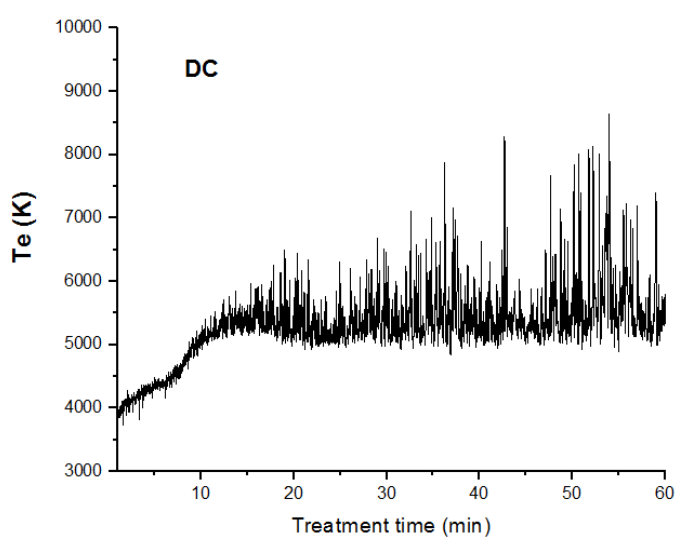

(a)

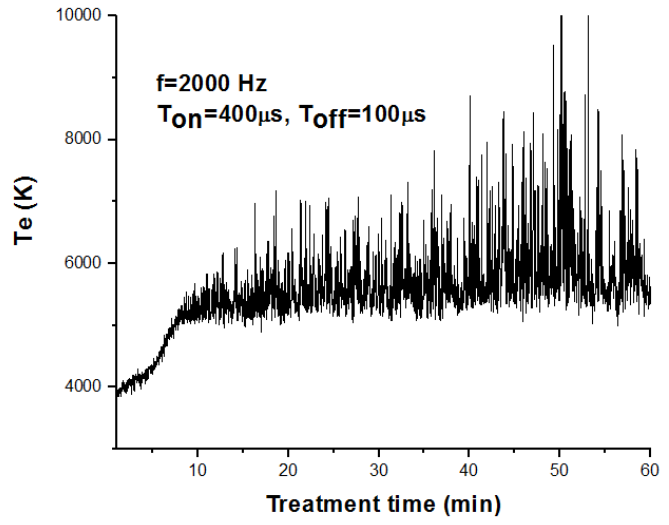

(b)

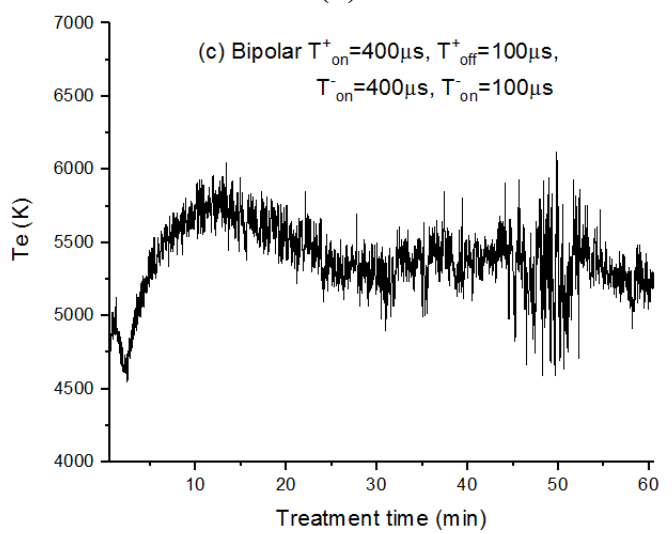

(c)

Figure 4: Plasma temperature as a function of treatment time for: (a) DC; (b) Unipolar; and (c) Bipolar current modes for $4 \mathrm{~g} / \mathrm{l} \mathrm{Na} \mathrm{SiO}_{3}$ electrolyte. 

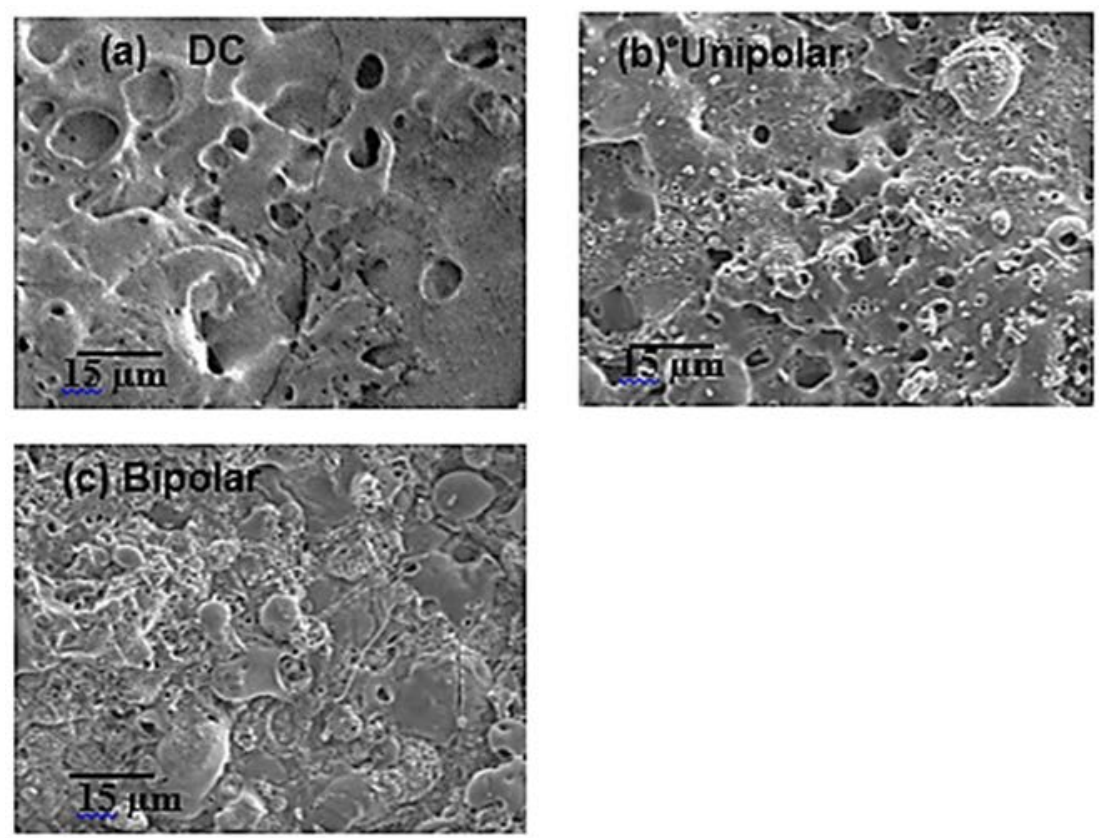

Figure 5: SEM micrographs showing surface morphology of oxide coating after 60 minutes treatment time on $\mathrm{Al}$ for: (a) DC; (b) Unipolar; and (c) Bipolar current modes.

The high spike temperatures generated by strong discharges melts the oxide and then traps gas into the melt pool, resulting in some porosity at the interface. SEM micrographs shown in Fig. 5(a) for DC and Fig. 5(b) for the unipolar mode show a number of relatively large pores in the coating. The diameter and features of the pancakes and pores can be considered as a guide to the strength of individual discharges and whether they were from the coating surface or from the interface. The deep holes suggest that the discharges are strong and penetrate deeply through the coating while, the small pores reflect relatively small surface discharges. For the case of bipolar PEO treatment, the flower-like shapes and smaller holes diameter shown in Fig. 5(c) as well as fewer pancake structures, indicates less strong discharges and a lower average base temperature as summarized in Fig. 4 and Table 2.

Fig. 6 is a typical SEM micrograph of a cross section of a coated Al alloy. PEO coatings consist of a three-layered structure: a porous outer layer with several large-sized, deep pores/cavities, an intermediate layer that is relatively dense that can provide good mechanical properties (e.g. wear) and a thin inner dense layer (coating/substrate interface barrier layer) that is well adhered to the substrate. It is the inner dense layer that eventually provides the best corrosion protection. However, due to the thickness of the interface barrier layer, only two layers are often reported when presenting SEM cross-sectional and micrographs [32].

Fig. 7 presents EDS spectra from positions 1 (porous layer), 2 (inner dense layer) and 3 (substrate) shown in Fig. 6. Due to the voids and pores in the coating outer layer, the silicon content is much higher than that in the inner region since the porous layer can trap the silicate electrolyte and allow silica to be formed after the plasma discharging. The inner layer 


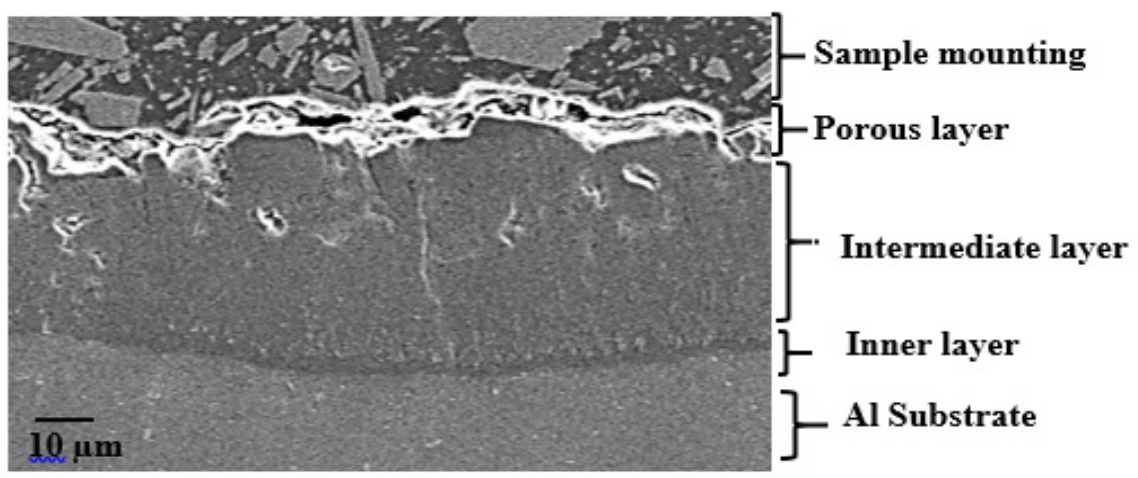

Figure 6: SEM micrograph of cross section of PEO coating on Al alloy produced using a bipolar current mode.

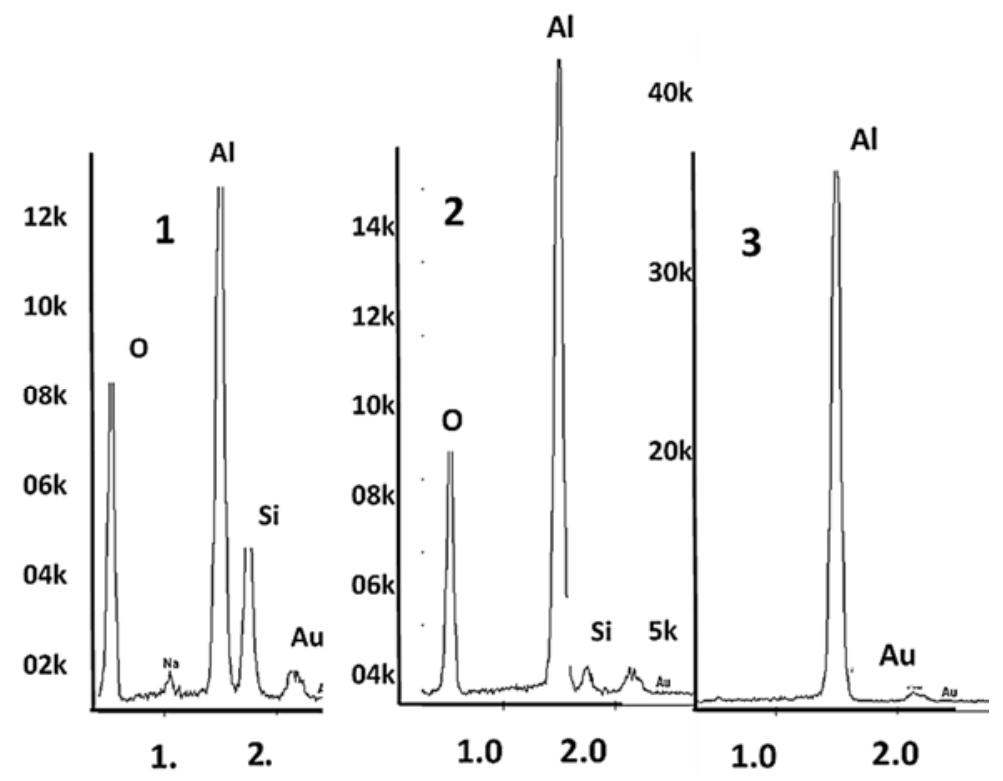

Figure 7: EDX analysis from (1) outer and (2) inner regions of the coated Al samples and for the substrate (region 3).

contains very little $\mathrm{Si}$ and no $\mathrm{Na}$ from the electrolyte. Aluminum and oxygen are the two major constituents of the inner layer of the coatings. An enhanced concentration of elements from the electrolyte in the outer, porous layer of the coating is commonly observed in the PEO processing of aluminium alloys [33].

Fig. 8(a)-(f) present cross-sectional SEM micrographs of the coatings for the three current modes, and treatment times of 15 and 60 minutes. The coating thicknesses after 60 minutes was much higher for the DC current mode $(77.0 \pm 4.0 \mu \mathrm{m})$ than for the unipolar $(47.0 \pm 2.3 \mu \mathrm{m})$ or bipolar $(48.0 \pm 2.4 \mu \mathrm{m})$ modes. The higher oxide growth rate for the DC current mode comes at the expense of higher porosity within the coating, including near the oxide-metal 
interface (Fig. 8(a)). The coating for the unipolar current mode appears to be well bonded to the substrate but there is still significant porosity within the coating (Fig. 8(c)). The bipolar current mode, although it results in a similar thickness coating as the unipolar mode, produces a more dense coating with a third layer (coating substrate interface) clearly visible (Fig. 8(e)). These cross-sectional observations are consistent with what was observed both with the coating surface morphology (Fig. 5) and plasma temperatures (Fig. 4 and Table 2). The very high-energy (temperature) discharges produced with the DC current mode, lead to the "pancake" structure and discharge channels that extend to the oxide metal interface. This also leads to higher porosity. The discharges are moderated by use of a unipolar or bipolar current mode, giving higher quality coatings.

A bipolar current mode is particularly effective in preventing the development of longlived, very large micro-discharges. The $\mathrm{T}_{\text {off }}$ period helps the local molten oxide cool down before another pulse is initiated. The $\mathrm{T}_{\text {on }}$ period provides sufficient time for sintering, and a hard coating with minimum porosity is produced [34].
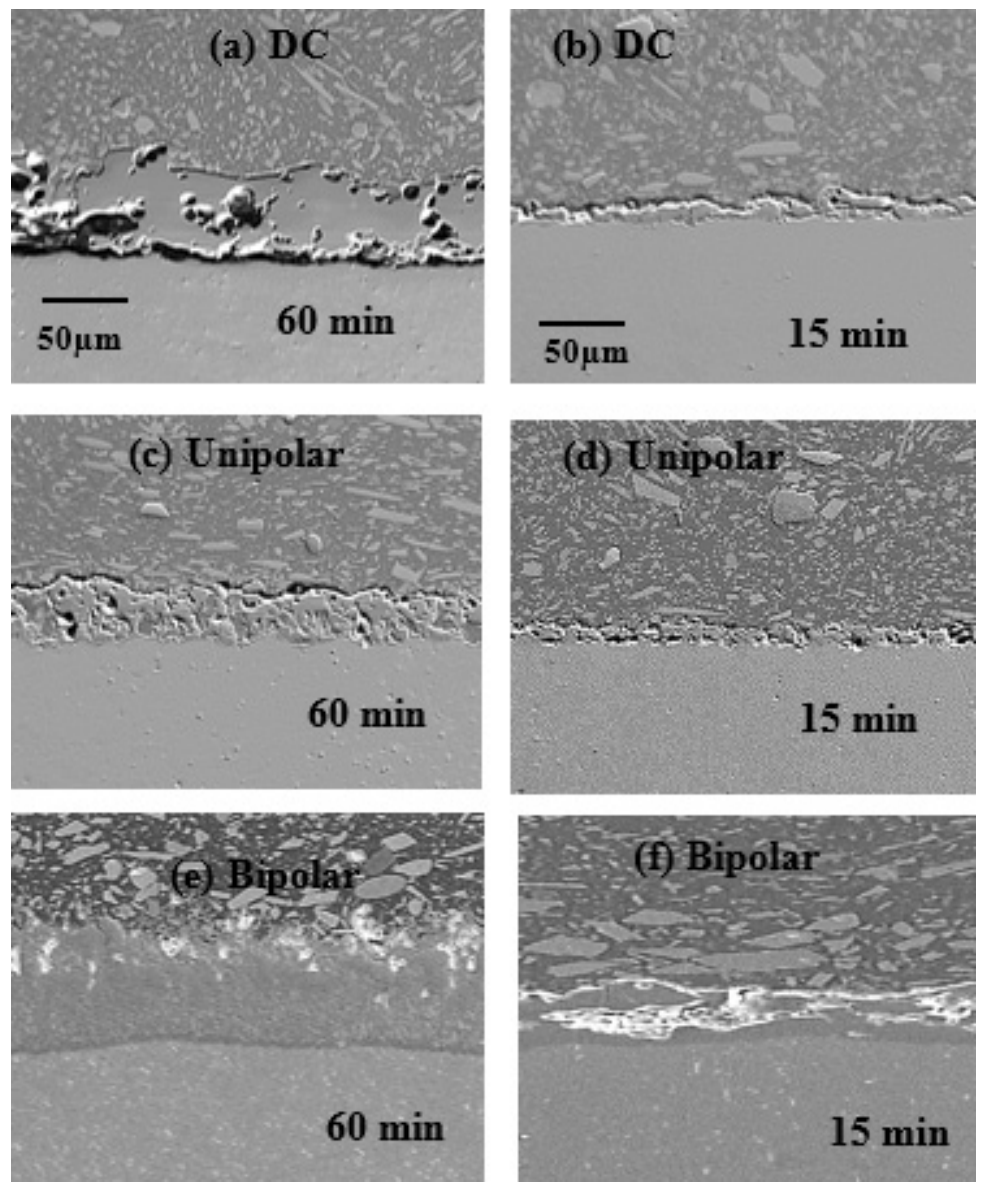

Figure 8: Cross-section micrographs of the oxide ceramic surface layers formed after 15 and 60 minutes treatment time and different current modes (electrolyte concentration $4 \mathrm{~g} / 1 \mathrm{Na}_{2} \mathrm{SiO}_{3}$ ). 


\subsection{Corrosion testing}

The potentiodynamic polarization curves of the uncoated 1100 alloy (S0) and the samples coated using DC (S1), unipolar (S2) and bipolar (S3) current modes are shown in Fig. 9. Values for the corrosion potential $\left(\mathrm{E}_{\text {corr }}\right)$, corrosion current density $\left(\mathrm{i}_{\mathrm{corr}}\right)$, and polarization resistance (Rp) obtained from the curves in Fig. 9 are summarized in Table 3.

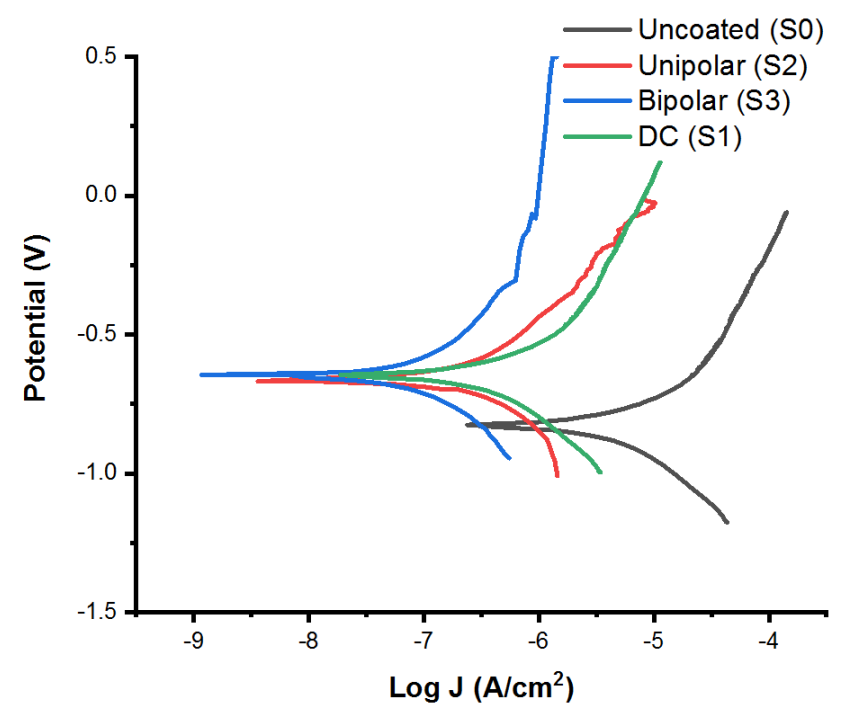

Figure 9: Potentiodynamic polarization curves of the uncoated ( $\mathrm{S} 0)$ and coated samples using DC (S1), unipolar (S2) and bipolar (S3) current modes.

Table 3: Potentiodynamic polarization corrosion test results in $3.5 \% \mathrm{wt} \mathrm{NaCl}$ solution.

\begin{tabular}{|c|c|c|c|}
\hline Samples & $\begin{array}{c}\mathbf{E}_{\text {corr }} \\
\mathbf{V}\end{array}$ & $\begin{array}{c}\mathbf{I}_{\text {corr }} \\
\boldsymbol{\mu A} / \mathbf{c m}^{\mathbf{2}}\end{array}$ & $\begin{array}{c}\mathbf{R}_{\mathbf{p}} \\
\mathbf{M} \boldsymbol{\Omega} / \mathbf{c m}^{2}\end{array}$ \\
\hline S0 Uncoated & -0.875 & 3.98 & 15.9 \\
\hline S1 DC & -0.723 & 0.177 & 166.0 \\
\hline S2 Unipolar & -0.72 & 0.098 & 367.5 \\
\hline S3 Bipolar & -0.675 & 0.036 & 1987.2 \\
\hline
\end{tabular}

The data clearly show the enhanced corrosion resistance provided by the PEO coatings: more noble $E_{\text {corr }}$, reduced $i_{\text {corr }}$ and higher Rp. Ranked in terms or their effectiveness as corrosion prevention coatings, they are: Bipolar $>$ Unipolar $>$ DC. This can then be related back to the ability to form a less porous, and more compact, microstructure as seen in the cross-sectional SEM micrographs in Fig. 8. The structure produced by a DC current mode gives the least corrosion resistance since there are pores at the coating-substrate interface (Fig. 8(a)). A bi-polar current mode produces a particularly effective corrosion resistant coating since there is a clear evidence for a thin interface barrier layer (Fig. 8(e)). As noted earlier, the structure of the PEO coatings can be related back to the nature and intensity of the micro discharges as seen in Fig. 4 and summarized in Table 2. 


\section{CONCLUSIONS}

Three different current modes (DC, unipolar, bipolar) were used to produce oxide coatings on an 1100 aluminum alloy using PEO in an alkaline silicate electrolyte. Measurement and analysis of the visible and NUV wavelength emissions from plasmas using OES provided a valuable diagnostic tool for the understanding the processes in the PEO plasma. The plasma electron concentration was calculated to be from $1.5 \pm 0.23 \times 10^{22} \mathrm{~m}^{-3}$ to $2.4 \pm 0.36$ $\times 10^{22} \mathrm{~m}^{-3}$, while plasma electron temperatures were found to be in the range of $4,500 \pm 450 \mathrm{~K}$ to $10,000 \pm 1,000 \mathrm{~K}$.

The application of the pulsed bipolar current mode, compared to the DC or unipolar modes, reduced both the magnitude of the high temperature spikes and the average plasma temperature. The magnitude and frequency of these temperature spikes (micro-sparking) affected the microstructure, morphology and chemistry of the oxide coating.

In general terms, the PEO coatings on aluminum consisted of a three-layer structure: an outer porous layer, an inner dense layer, and a thin interface barrier layer. This interface layer was most evident for coatings produced using bipolar current mode. EDS studies showed that the $\mathrm{Si}$, and to a lesser extent $\mathrm{Na}$, originating from the electrolyte, were concentrated in the porous layer. The porous outer layer and the dense inner layer have been referred to as the "technological layer" and "working layer", respectively, to reflect the fact that it is the compact oxide in the inner region that provides the wear and corrosion resistance [33]. The DC current mode, and associated long-lived, very large microdischarges, produced a thicker porous outer region and, even, porosity at the metal-coating interface that would, and did, adversely affect the corrosion resistance.

As noted, the use of the bipolar current mode resulted in what is known as "softer sparking" [7] producing a less porous, more compact coating with smother surface and the highest corrosion resistance of the coatings fabricated using the three different current modes. In terms of their effectiveness in producing corrosion resistant coatings, the three current modes are ranked: Bipolar $>$ Unipolar $>$ DC.

\section{REFERENCES}

[1] Miller, W.S. et al., Recent development in aluminum alloys for the automotive industry. Materials Science and Engineering, A280, pp. 37-49, 2000.

[2] Rambabu, P., Prasad, N.E., Kutumbarao, V.V. \& Wanhill, R.J.H., Aluminium alloys for aerospace applications. Aerospace Materials and Material Technologies, eds N. Eswara Prasad \& R.J.H. Wanhill, Springer Science and Business Media: Singapore, pp. 29-52, 2017.

[3] Total Materia, Surface treatment of aluminium and aluminium alloys. www.totalmateria.com/Article67.htm. Accessed on: 16 Jan. 2019.

[4] Hanshan, D. (ed), Surface Engineering of Light Alloys, Woodhead Publishing: Cambridge, UK, 2010.

[5] Yerokhin, A. \& Khan, R.H.U., Anodising of light alloys. Surface Engineering of Light Alloys, ed. H. Dong, Woodhead Publishing: Cambridge, UK, pp. 83-109, 2010.

[6] Yerokhin, A.L., Nie, X., Leyland, A., Matthews, A. \& Dowey, S.J., Plasma electrolysis for surface engineering. Surface and Coatings Technology, 122, pp. 73-93, 1999.

[7] Tsai, D.-S. \& Chou, C.-C., Review of the soft sparking issues in plasma electrolytic oxidation. Metals, 8(2), pp. 1-22, 2018. DOI: 10.3390/met8020105.

[8] Jedrusik, J., Debowska, A. \& Kopia, A., Characterisation of oxide coatings produced on aluminium alloys by MAO and chemical methods. Archives of Metallurgy and Materials, 63(1), pp. 125-128, 2018. 
[9] Hussein, R.O., Nie, X. \& Northwood, D.O., An investigation of ceramic coating growth mechanisms in Plasma Electrolytic Oxidation (PEO) processing. Electrochimica Acta, 112, pp. 111-119, 2013.

[10] Jiang, B.L. \& Wang, Y.M., Plasma electrolytic oxidation treatment of aluminium and titanium alloys. Surface Engineering of Light Alloys, ed. H. Dong, Woodhead Publishing: Cambridge, UK, pp. 110-146, 2010.

[11] Hussein, R.O., Nie, X. \& Northwood, D.O., Influence of process parameters on electrolytic plasma discharging behaviour and aluminum oxide coating microstructure. Surface and Coatings Technology, 205, pp. 1659-1667, 2010.

[12] Al Bosta, M.M.S. \& Ma, K.-J., Suggested mechanism for the MAO ceramic coating on aluminium substrates using bipolar current mode in the alkaline silicate electrolytes. Applied Surface Science, 308, pp. 121-138, 2014.

[13] Hussein, R.O., Northwood, D.O. \& Nie, X., Coating growth behavior during the plasma electrolytic oxidation process. Journal of Vacuum Science and Technology A, 28(4), pp. 766-773, 2010.

[14] Egorkin, V.S., Gnedenkov, S.V., Sinebryukhov, S.L., Vyaliy, L.E. \& Gnedenkov, R.G.C.A.S., Increasing thickness and protective properties of PEO-coatings on aluminum alloy. Surface and Coatings Technology, 334, pp. 29-42, 2018.

[15] Dehnavi, V., Surface modification of aluminum alloys by plasma electrolytic oxidation. Electronic Thesis and Dissertation Repository, 2311, 2014. https://ir.lib.uwo.ca/etd/2311.

[16] Rakoch, A.G., Khokhlov, V.V., Bautin, V.A., Lebedeva, N.A., Magurova, Y.V. \& Bardin, I.V., Model concepts on the mechanism of microarc oxidation of metal materials and the control over this process. Protection of Metals and Physical Chemistry of Surfaces, 42, pp. 158-169, 2006.

[17] Yang, K. \& Cao, B., Electrical characteristics identification of dielectric film breakdown during plasma electrolytic oxidation process. Materials Letters, 143, pp. 177-180, 2015.

[18] Maximov, A.I. \& Khlustova, A.V., Optical emission from plasma discharge in electrochemical systems applied for modification of material surfaces. Surface and Coatings Technology, 201, pp. 8782-8788, 2007.

[19] Hussein, R.O., Nie, X., Northwood, D.O., Yerokhin, A. \& Matthews, A., Spectroscopic study of electrolytic plasma and discharging behaviour during the plasma electrolytic oxidation (PEO) process. Journal of Physics D: Applied Physics, 43, p. 105203, 2010.

[20] Northwood, D.O., Hussein, R.O. \& Nie, X., Environmentally friendly surface treatment of light alloy materials for automotive applications. Proceedings of the 18th International Corrosion Congress, Perth, Australia, pp. 825-836, 2011.

[21] Dunleavy, C.S., Golosnoy, I.O., Curran, J.A. \& Clyne, T.W., Characterisation of discharge events during plasma electrolytic oxidation. Surface and Coatings Technology, 203, pp. 3410-3419, 2009.

[22] Sullivan, S.A., Experimental study of the absorption in distilled water, artificial sea water, and heavy water in the visible region of the spectrum. Journal of the Optical Society of America, 53, pp. 962-968, 1963.

[23] Gigososa, M., Gonzalez, M. \& Cardenoso, V., Computer simulated Balmer-alpha, -beta and -gamma Stark line profiles for non-equilibrium plasmas diagnostics. Spectrochim. Acta Part B, 58, pp. 1489-1504, 2003.

[24] Czernikowski, A. \& Chapelle, J., Experimental-study of Stark-broadening of the argon-I 430.01 nm line. Acta Phys. Pol. A, 63, pp. 67-75, 1983. 
[25] García, M.C., Rodero, A., Sola, A. \& Gamero, A., Spectroscopic study of a stationary surface-wave sustained argon plasma column at atmospheric pressure. Spectrochimica Acta Part B: Atomic Spectroscopy, 55, pp. 1733-1745, 2000.

[26] Griem, H.R., Principles of Plasma Spectroscopy, Cambridge University Press: Cambridge, 1997.

[27] Hussein, R.O., Zhang, P., Northwood, D.O. \& Nie, X., Improving the corrosion resistance of magnesium alloy AJ62 by a plasma electrolytic oxidation (PEO) coating process. Corrosion and Materials, 36, pp. 38-49, 2011.

[28] Simchen, F., Sieber, M. \& Lampke, T., Electrolyte influence on ignition of plasma electrolytic oxidation processes on light metals. Surface and Coatings Technology, 315, pp. 205-213, 2017.

[29] Klapkiv, M.D., Nykyforchyn, H.M. \& Posuvailo, V.M., Spectral analysis of an electrolytic plasma in the process of synthesis of aluminum oxide. Material Science, 30(3), pp. 333-343, 1995.

[30] Cen, J. et al., Electron density measurement of a lightning stepped leader by oxygen spectral lines. AIP ADVANCES, 8, p. 085019, 2018.

[31] Chang, X., Yuan, P., Gen, J. \& Wand, X., Variation of the channel temperature in the transmission of lightning leader. Journal of Atmospheric and Solar-Terrestrial Physics, 159, pp. 41-47, 2017.

[32] Safa-Yilmaz, M. \& Sahin, O., Applying high voltage cathodic pulse with various pulse durations on aluminium via micro-arc oxidation (MAO). Surface and Coatings Technology, 347, pp. 278-285, 2018.

[33] Sieber, M., Simchen, F., Morgenstern, R., Scharf, I. \& Lampke, T., Plasma electrolytic oxidation of high-strength aluminium alloys substrate effect on wear and corrosion performance. Metals, 8(5), p. 356, 2018.

[34] Hussein, R.O., Northwood, D.O. \& Nie, X., The influence of pulse timing and current mode on the microstructure and corrosion behaviour of a plasma electrolytic oxidation (PEO) coated AM60B magnesium alloy. J. Alloys and Compounds, 541, pp. 41-48, 2012. 